\title{
Preface
}

\section{Auxetics and other systems of "negative" characteristics}

This is the eleventh issue of physica status solidi $(b)$ focussed on materials and models exhibiting negative Poisson's ratio (PR), called auxetics, and other systems of "negative" characteristics [1]. It contains 22 papers, from which the first 17 papers concern auxetics, the following 4 are related to negative stiffness, and the last paper describes auxetic-like magneto-elastic effect.

The issue starts from the paper by Chan Soo $\mathrm{Ha}$, Michael E. Plesha, and Roderic S. Lakes describing a chiral, isotropic model with negative Poisson's ratio [2]. The following paper by Teik-Cheng Lim presents another macroscopic model of auxetic properties [3]. The elastic properties of hexagonal auxetics under pressure are discussed by Robert V. Goldstein, Valentin A. Gorodtsov, and Dmitry S. Lisovenko [4].

Experimental studies of temperature, pressure and time influence on the induction of auxetic response in needle-punched nonwovens are described by Prateek Verma, Meisha L. Shofner, Angela Lin, Karla B. Wagner, and Anselm C. Griffin [5]. Kim Alderson, Shonali Nazare, and Andrew Alderson discuss large-scale extrusion of auxetic polypropylene fibre [6].

The next six papers present microscopic models of auxetics. Duc Tam Ho, Soon-Dong Park, Soon-Yong Kwon, Tong-Seok Han, and Sung Youb Kim discuss negative Poisson's ratio in cubic materials along principal directions [7]. D. S. Lisovenko, J. A. Baimova, L. Kh. Rysaeva, V. A. Gorodtsov, A. I. Rudskoy, and $S$. V. Dmitriev analyse elastic properties of diamondlike carbon nanostructures with cubic anisotropy

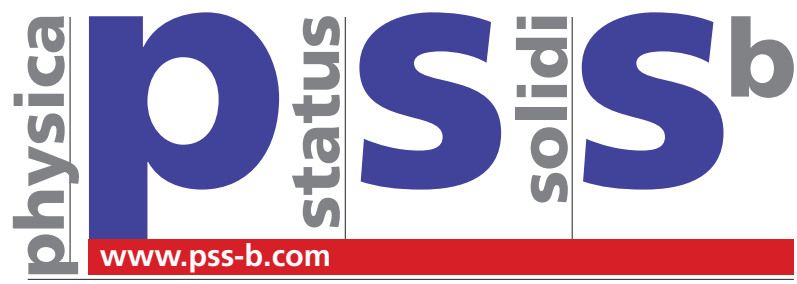

basic solid state physics
[8]. Viet Hung Ho, Duc Tam Ho, Soon-Yong Kwon, and Sung Youb Kim study negative Poisson's ratio in periodic porous graphene structures [9]. S. V. Dmitriev, E. A. Korznikova, D. I. Bokij, and K. Zhou demonstrate auxeticity resulting from nonlinear vibrational modes in a planar honeycomb lattice [10]. Mikołaj Bilski and Krzysztof W. Wojciechowski simulate purely entropic planar systems of low symmetry to illustrate a possibility of tailoring Poisson's ratio by introducing auxetic layers [11]. Jakub Narojczyk, Mikołaj Kowalik, and Krzysztof W. Wojciechowski consider the influence of nanochannels on Poisson's ratio of aperiodic (degenerate) crystal of hard dimers [12].

Auxetic composites are the subject of the following six papers. Lin Zhou, Lili Jiang, and Hong $\mathrm{Hu}$ describe auxetic composites made of three-dimensional textile structure and polyurethane foam [13]. Igor Shufrin, Elena Pasternak, and Arcady V. Dyskin analyse deformations of reinforced-core auxetic assemblies by close-range photogrammetry [14]. Tomasz Strek, Hubert Jopek, and Agnieszka Fraska discuss torsions of elliptical composite beams with auxetic phase [15]. Hubert Jopek studies bending of a fibrous composite reinforced with auxetic phase by computer simulations [16]. H. Mohanraj, S. L. M. Filho Ribeiro, T. H. Panzera, F. Scarpa, I. R. Farrow, R. Jones, A. Davies-Smith, C. D. L. Remillat, P. Walters, and H.$X$. Peng present hybrid auxetic foam and perforated plate composites for human body support [17]. Tomasz Strek, Hubert Jopek, and Eligiusz Idczak design two-phase auxetic structures by numerical optimization techniques [18]. 
Another four papers discuss the phenomenon of negative stiffness (or compressibility). Stability of twodimensional discrete mass-spring systems with negative stiffness springs is studied by Maxim Esin, Elena Pasternak, and Arcady Dyskin [19]. Daphne Attard, Roberto Caruana-Gauci, Ruben Gatt, and Joseph N. Grima discuss negative linear compressibility in models consisting of rotating rigid units [20]. Nano networks exhibiting negative linear compressibility are considered by Joseph N. Grima, Edera P. Degabriele, and Daphne Attard [21]. Effects of negative stiffness on bulk and shear responses of ferroelastic materials via phase field modelling in two dimensions are described by Yun-Che Wang and Meng-Wei Shen [22].

Finally, Ganesh Raghunath, Alison Flatau, Hui Wang, and Ruqian $W u$ present and discuss experimental data and computer simulation results which reveal magnetoelastic auxetic-like behaviour in galfenol [23].

We thank all the contributors of this thematic issue for submitting their papers. We are grateful to all the reviewers for valuable comments. Organizational efforts of Mr. Keith M. Azzopardi and Dr. Jean-Pierre Brincat, without whom this volume would not contain some of the submissions, are also acknowledged.

Krzysztof W. Wojciechowski (Institute of Molecular Physics, Polish Academy of Sciences, Poznan, Poland)

Fabrizio Scarpa (Advanced Composites Centre for Innovation and Science, University of Bristol, UK) Joseph N. Grima (Faculty of Science, University of Malta)

Andrew Alderson (Materials and Engineering Research Institute, Sheffield Hallam University, UK)

\section{References}

[1] K. W. Wojciechowski, F. Scarpa, J. N. Grima, A. Alderson, Phys. Status Solidi B 252(7), 1421-1425 (2015).

[2] C. S. Ha, M. E. Plesha, and R. S. Lakes, Phys. Status Solidi B 253(7), 1243-1251 (2016), this issue.

[3] T.-C. Lim, Phys. Status Solidi B 253(7), 1252-1260 (2016), this issue.

[4] R. V. Goldstein, V. A. Gorodtsov, and D. S. Lisovenko, Phys. Status Solidi B 253(7), 1261-1269 (2016), this issue.
[5] P. Verma, M. L. Shofner, A. Lin, K. B. Wagner, and A. C. Griffin, Phys. Status Solidi B 253(7), 1270-1278 (2016), this issue.

[6] K. Alderson, S. Nazare, and A. Alderson, Phys. Status Solidi B 253(7), 1279-1287 (2016), this issue.

[7] D. T. Ho, S.-D. Park, S.-Y. Kwon, T.-S. Han, and S. Y. Kim, Phys. Status Solidi B 253(7), 1288-1294 (2016), this issue.

[8] D. S. Lisovenko, J. A. Baimova, L. Kh. Rysaeva, V. A. Gorodtsov, A. I. Rudskoy, and S. V. Dmitriev, Phys. Status Solidi B 253(7), 1295-1302 (2016), this issue.

[9] V. H. Ho, D. T. Ho, S.-Y. Kwon, and S. Y. Kim, Phys. Status Solidi B 253(7), 1303-1309 (2016), this issue.

[10] S. V. Dmitriev, E. A. Korznikova, D. I. Bokij, and K. Zhou, Phys. Status Solidi B 253(7), 1310-1317 (2016), this issue.

[11] M. Bilski and K. W. Wojciechowski, Phys. Status Solidi B 253(7), 1318-1323 (2016), this issue.

[12] J. W. Narojczyk, M. Kowalik, and K. W. Wojciechowski, Phys. Status Solidi B 253(7), 1324-1330 (2016), this issue.

[13] L. Zhou, L. Jiang, and H. Hu, Phys. Status Solidi B 253(7), 1331-1341 (2016), this issue.

[14] I. Shufrin, E. Pasternak, and A. V. Dyskin, Phys. Status Solidi B 253(7), 1342-1358 (2016), this issue.

[15] T. Strek, H. Jopek, and A. Fraska, Phys. Status Solidi B 253(7), 1359-1368 (2016), this issue.

[16] H. Jopek, Phys. Status Solidi B 253(7), 1369-1377 (2016), this issue.

[17] H. Mohanraj, S. L. M. Filho Ribeiro, T. H. Panzera, F. Scarpa, I. R. Farrow, R. Jones, A. Davies-Smith, C. D. L. Remillat, P. Walters, and H.-X. Peng, Phys. Status Solidi B 253(7), 1378-1386 (2016), this issue.

[18] T. Strek, H. Jopek, and E. Idczak, Phys. Status Solidi B 253(7), 1387-1394 (2016), this issue.

[19] M. Esin, E. Pasternak, and A. Dyskin, Phys. Status Solidi B 253(7), 1395-1409 (2016), this issue.

[20] D. Attard, R. Caruana-Gauci, R. Gatt, and J. N. Grima, Phys. Status Solidi B 253(7), 1410-1418 (2016), this issue.

[21] J. N. Grima, E. P. Degabriele, and D. Attard, Phys. Status Solidi B 253(7), 1419-1427 (2016), this issue.

[22] Y.-C. Wang and M.-W. Shen, Phys. Status Solidi B 253(7), 1428-1439 (2016), this issue.

[23] G. Raghunath, A. B. Flatau, H. Wang, and R. Wu, Phys. Status Solidi B 253(7), 1440-1448 (2016), this issue. 